\title{
Research on Watershed Water Cycle Simulation Method Based on System Dynamics
}

\author{
Jiang $\mathrm{Wu}^{1,2}$, Jin $\mathrm{Chen}^{1,2}$, Jijun $\mathrm{Xu}^{1,2}$, Yongqiang Wang ${ }^{1,2}$, Qingqing $\mathrm{Li}^{1,2}$ \\ ${ }^{1}$ Changjiang River Scientific Research Institute \\ ${ }^{2}$ Hubei Key Laboratory of River Basin Water Resources and Ecological Environment Science
}

\begin{abstract}
The process of rainfall and runoff in the watershed is nonlinear which strongly depends on precipitation, evaporation, infiltration and hydrodynamic characteristics of soil. Due to the random and complex nature of the natural state of runoff, the temporal and spatial variability of rainfall and runoff in the watershed is extremely complicated. In view of the ability of system dynamics to describe multivariate, high order, multi-loop, strong nonlinear and complex feedback relationships, and to analyze the feedback between variables, the water cycle dynamics model is established by using system dynamics method. According to the dynamic characteristics of hydrological process, the dynamic process of rainfall to runoff is analyzed, and the relationships between the variables in the model are characterized by specific differential equations. The case study in the Zhexi watershed shows that this model can accurately simulate the process of water cycle in the watershed which also performs well on hydrological forecasting. It has certain practical significance for expanding new idea on hydrological forecasting modeling.
\end{abstract}

\section{Introduction}

System dynamics is a systematic scientific method to study the internal operating mechanism of the system. It studies the structural function and feedback mechanism of complex systems and analyzes the causal mechanism and dynamic behavior of the system ${ }^{[1,2]}$. System dynamics model is composed of a series of differential equations with time delays. It can solve nonlinear, multivariable, high-order, multiple feedback and complex time-varying mathematical problems. System dynamics mainly analyzes the feedback between variables, and the requirements for the accuracy of input data and model parameters are not high. It is widely used in dynamic characteristics analysis and complex system modeling ${ }^{[3,4]}$.

The instantaneous process of runoff is a nonlinear process that strongly depends on atmospheric precipitation, surface evaporation, infiltration and soil hydrodynamic characteristics. Due to the random complexity of the natural state of runoff and the mutual integration of mat surface factors at different spatial scales, the spatial and temporal variability of the river basin production and distribution is extremely complicated. The existing forecasting methods have insufficient description of the complex dynamic characteristics of rainfall and runoff mechanism. The forecast period is restricted by the process of precipitation and convergence, and parameters of the forecast models are difficult to determine. It is difficult to meet the requirements of real-time scheduling and joint optimization operation on the accuracy and forecast period of runoff forecasting. Considering the current status of hydrological forecasting, the system dynamics causal feedback loop is used to analyze the relationships between various forecasting factors. It can effectively reveal the interaction and feedback mechanism among various factors within complex systems. Therefore, the research on hydrological forecasting modeling method based on system dynamics can provide new ideas for hydrological forecasting modeling and also hope to achieve good hydrological forecasting effects.

\section{Water cycle dynamics model}

A conceptual hydrological model is able to simulate the various components of the process of rainfall to runoff. This paper takes accounts of the existing hydrological model which includes climatic factors and hydrological processes ${ }^{[5,6]}$. The simulation of watershed water balance is composed of canopy storage, surface soil storage, subsurface soil storage, and groundwater storage. Figure $\mathbf{1}$ shows the hydrological process of rainfall to runoff. 


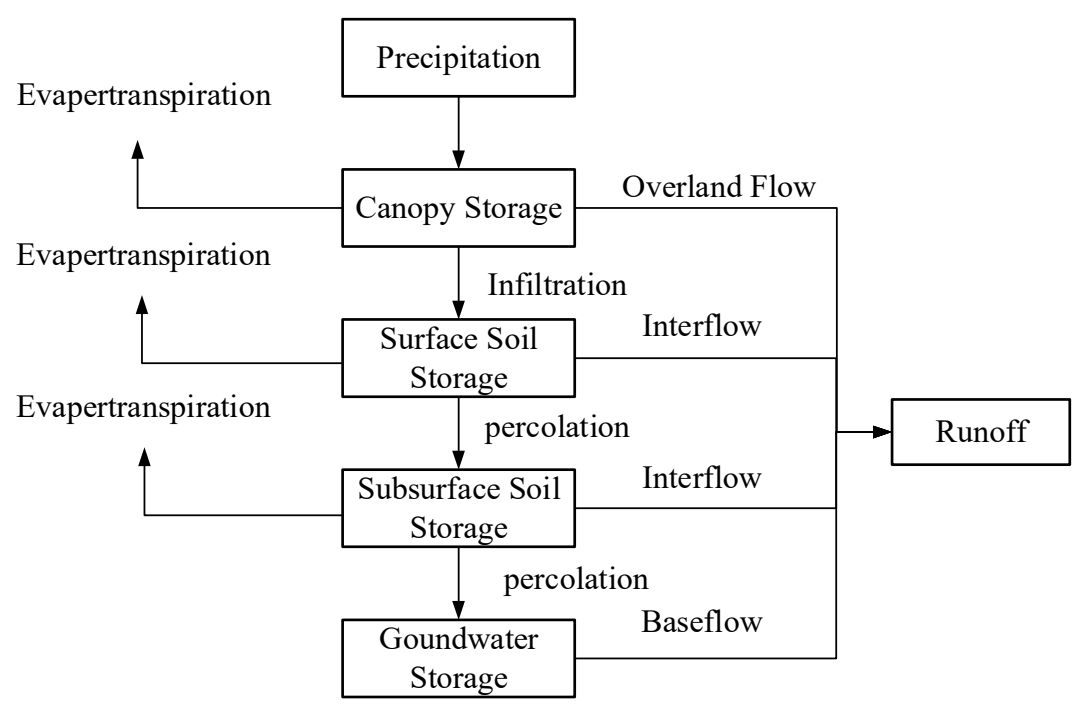

Figure 1 The hydrological process of rainfall to runoff

The system dynamics method based on feedback principle is used to simulate the hydrological process of watershed. System dynamics uses a series of nonlinear differential equations to describe the complex feedback relationships of various variables of the system. It considers that the feedback loop structure controls the dynamic behavior of the system. In a positive feedback loop, the variables increase or decrease together. While in a negative feedback loop, the factors in the loop are maintained in an equilibrium state. System dynamics methods help to identify the source of the behavior and understand the feedback mechanism of the system. In view of the system dynamics, the dynamic behavior of the hydrological system is a series of transformation caused by the feedback loop structure. Since the internal and external conditions of hydrological system are inconsistent, the comprehensive analysis of the complex feedback relationship can help to understand the watershed better. Based on the hydrological process mentioned above, the water cycle dynamics model of the hydrological process is established as shown in Figure 2. In Figure 2, "+" indicates positive correlation and "-." indicates negative correlation. 


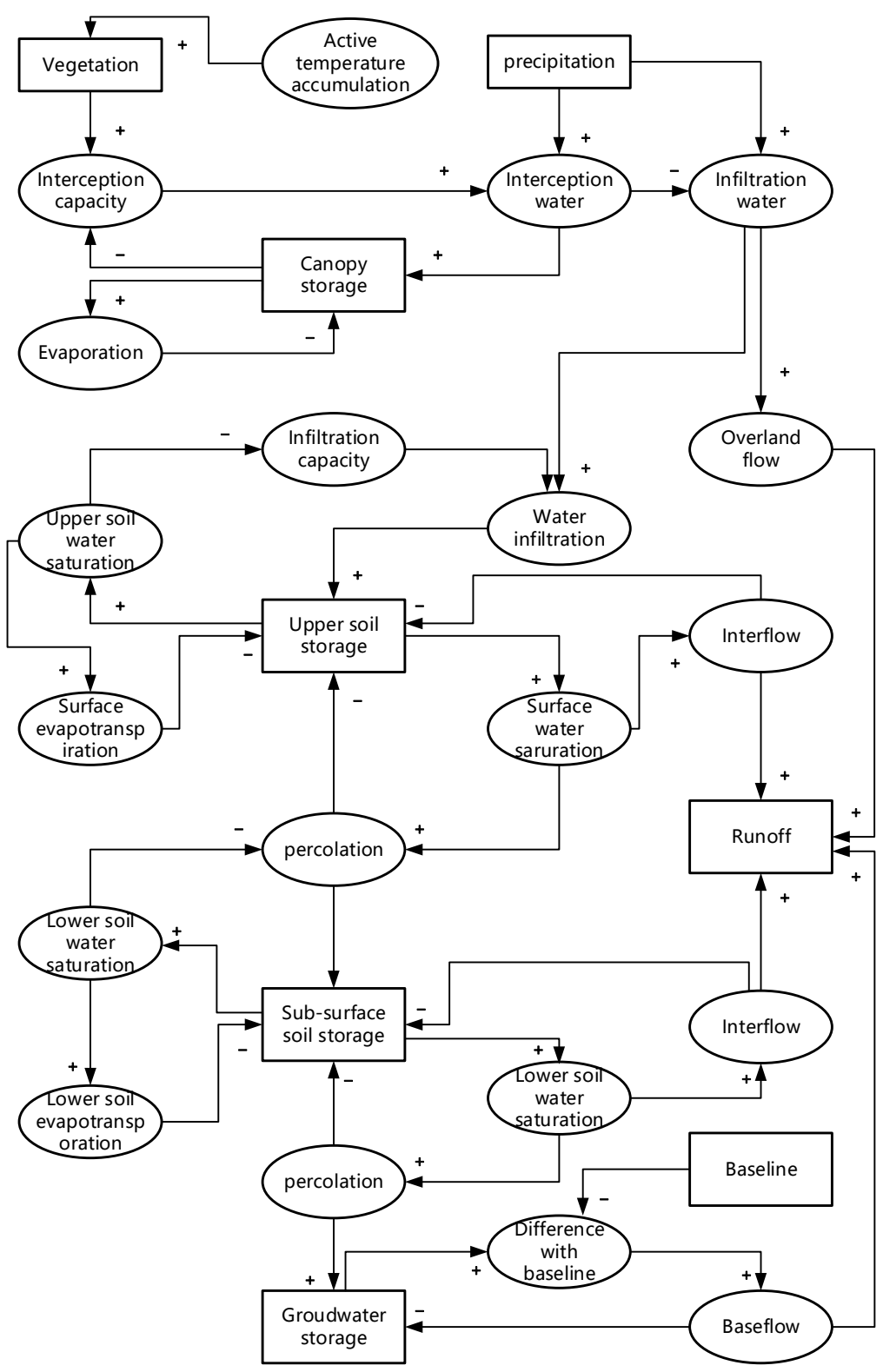

Figure 2 Water cycle dynamics model of the hydrological process

Based on the water balance principle, each layer of soil and flow concentration are described as below.

(a) Canopy storage

$$
\begin{aligned}
& \frac{\mathrm{d} S 1}{\mathrm{~d} t}=R_{c}-c_{1} T \\
& R_{c}=\min \left[P, C_{c}-S 1\right]
\end{aligned}
$$

Where $S 1$ denotes the water in the canopy storage, $R_{c}$ denotes the interception rate, $c_{1}$ denotes the evaporation coefficient, $P$ denotes the precipitation and $C_{c}$ denotes canopy interception capacity.

(b) Surface soil storage

$$
\frac{\mathrm{d} S 2}{\mathrm{~d} t}=R_{C I}-R_{E 1}-R_{F 1}-R_{\mathrm{P} 1}
$$

Where $S 2$ denotes the water in surface soil storage,
$R_{C I}, R_{E 1}, R_{F 1}$ and $R_{\mathrm{P} 1}$ denotes the rates of infiltration, evapotranspiration, interflow and percolation respectively in the surface soil storage.

(c) Subsurface soil storage

$$
\frac{\mathrm{d} S 3}{\mathrm{~d} t}=R_{\mathrm{P} 1}-R_{E 2}-R_{F 2}-R_{\mathrm{P} 2}
$$

Where $S 3$ denotes the water in surface soil storage, $R_{\mathrm{P} 1}, R_{E 2}, R_{F 2}$ and $R_{\mathrm{P} 2}$ denotes the rates of infiltration, evapotranspiration, interflow and percolation respectively in the subsurface soil storage.

(d) Groundwater storage

$$
\frac{\mathrm{d} S 4}{\mathrm{~d} t}=R_{\mathrm{P} 2}-R_{B F}
$$

Where $S 4$ denotes the water in groundwater storage, $R_{B F}$ denotes the base flow.

(e) Runoff equation 


$$
\begin{aligned}
& R=R 1+R_{F 1}+R_{F 2}+R_{B F} \\
& Q=\operatorname{SMTH} 3\left(R \cdot A, t_{\text {delay }}, \mathrm{Q}_{0}\right)
\end{aligned}
$$

Where $Q$ denotes the runoff, $\mathrm{U}_{\mathrm{c}}$ denotes a unit conversion coefficient, $t_{\text {delay }}$ denotes the average delay time and $\mathrm{Q}_{0}$ denotes the initial runoff.

\section{Case study}

\subsection{Study area}

Zhexi river basin is located in the central part of Zishui river in Hunan Province. The area of Zhexi river basin is $21833 \mathrm{~km}^{2}$ and the average annual flow is $586 \mathrm{~m}^{3} / \mathrm{s}$. It belongs to the tropical warm and humid climate of East Asian monsoon. It is hot and rainy in summer, cold and dry in winter. It belongs to the typical southern climate characteristics of China. Precipitation is the only source of runoff in the river basin. According to the distribution of existing hydrological stations and characteristics of Zhexi watershed, the whole watershed is divided into six subbasins as shown in Figure 3.

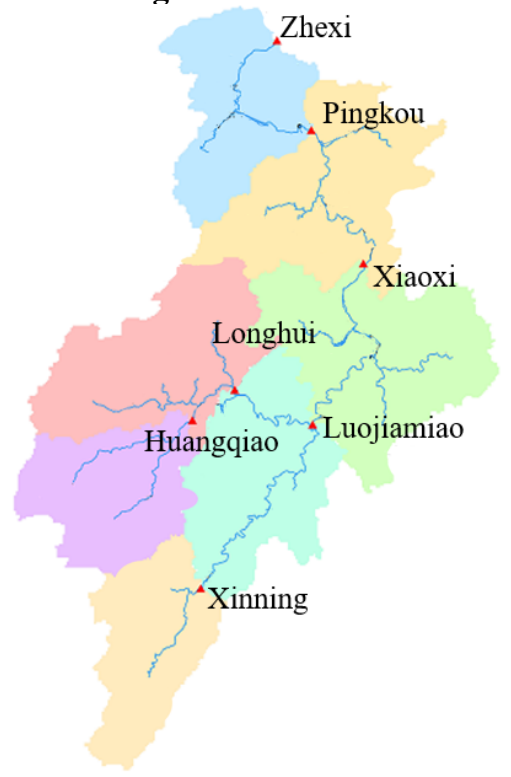

Figure 3 Sub-basins of Zhexi watershed

\subsection{Result and discussion}

In the model, observed data such as air temperature, rainfall and runoff and parameters are the key to solve the problem above. The step of the model is set as $1 \mathrm{~h}$, and the simulation period is from 2004-1-1 to 2014-12-31. Runoff on all the sections are obtained by the simulation of the water cycle dynamics model. The accuracy of simulation results of all the sections are evaluated by the index of $M A E, M R E, R^{2}$ and $R M S E$ as shown in Table 1. It can be seen from Table 1 that the performance of water cycle dynamics model is quite good, especially on the section of Luojiamiao, Xiaoxi and Zhexi. The index of $R^{2}$ exceeds 0.9 which means that the forecasting accuracy reaches level $A$. However, the simulation results in the Huangqiao and Xinning section are slightly worse. Since the flow of these two sections are too small and little observation errors can cause large deviations between the observed data and the actual one, it brings big difficulty to the prediction of flow on these two sections.

\begin{tabular}{|c|c|c|c|c|c|}
\hline Section & Period & $\begin{array}{c}M A E\left(\mathrm{~m}^{3}\right. \\
/ \mathrm{s})\end{array}$ & $\begin{array}{c}M R \\
E \\
\end{array}$ & $R^{2}$ & $\begin{array}{c}R M S E\left(\mathrm{~m}^{3}\right. \\
/ \mathrm{s})\end{array}$ \\
\hline \multirow{2}{*}{$\begin{array}{l}\text { Huangqi } \\
\text { ao }\end{array}$} & $\begin{array}{c}\text { Calibrati } \\
\text { on }\end{array}$ & 5.52 & $\begin{array}{c}0.11 \\
1\end{array}$ & $\begin{array}{c}0.8 \\
1\end{array}$ & 7.22 \\
\hline & $\begin{array}{c}\text { Validatio } \\
n\end{array}$ & 6.05 & $\begin{array}{c}0.12 \\
1\end{array}$ & $\begin{array}{c}0.7 \\
6\end{array}$ & 8.78 \\
\hline \multirow{2}{*}{ Xinning } & $\begin{array}{l}\text { Calibrati } \\
\text { on }\end{array}$ & 1.82 & $\begin{array}{c}0.10 \\
6\end{array}$ & $\begin{array}{c}0.8 \\
3\end{array}$ & 2.56 \\
\hline & $\begin{array}{c}\text { Validatio } \\
n\end{array}$ & 2.01 & $\begin{array}{c}0.11 \\
8\end{array}$ & $\begin{array}{c}0.7 \\
7\end{array}$ & 2.98 \\
\hline \multirow{2}{*}{ Longhui } & $\begin{array}{c}\text { Calibrati } \\
\text { on }\end{array}$ & 5.67 & $\begin{array}{c}0.09 \\
3\end{array}$ & $\begin{array}{c}0.9 \\
4\end{array}$ & 6.34 \\
\hline & $\begin{array}{c}\text { Validatio } \\
n\end{array}$ & 6.58 & $\begin{array}{c}0.10 \\
7\end{array}$ & $\begin{array}{c}0.8 \\
9\end{array}$ & 7.68 \\
\hline \multirow{2}{*}{$\begin{array}{c}\text { Luojiami } \\
\text { ao }\end{array}$} & $\begin{array}{c}\text { Calibrati } \\
\text { on }\end{array}$ & 12.14 & $\begin{array}{c}0.08 \\
8\end{array}$ & $\begin{array}{c}0.9 \\
7\end{array}$ & 13.12 \\
\hline & $\begin{array}{c}\text { Validatio } \\
\mathrm{n}\end{array}$ & 13.59 & $\begin{array}{c}0.09 \\
8\end{array}$ & $\begin{array}{c}0.9 \\
2\end{array}$ & 15.77 \\
\hline \multirow{2}{*}{ Xiaoxi } & $\begin{array}{c}\text { Calibrati } \\
\text { on }\end{array}$ & 15.87 & 0.09 & $\begin{array}{c}0.9 \\
6\end{array}$ & 17.99 \\
\hline & $\begin{array}{c}\text { Validatio } \\
n\end{array}$ & 18.78 & $\begin{array}{c}0.10 \\
5\end{array}$ & 0.9 & 20.87 \\
\hline \multirow{2}{*}{ Zhexi } & $\begin{array}{c}\text { Calibrati } \\
\text { on }\end{array}$ & 25.94 & 0.09 & $\begin{array}{c}0.9 \\
6\end{array}$ & 27.24 \\
\hline & $\begin{array}{c}\text { Validatio } \\
n\end{array}$ & 28.86 & $\begin{array}{c}0.10 \\
1\end{array}$ & $\begin{array}{c}0.9 \\
1\end{array}$ & 32.56 \\
\hline
\end{tabular}

Table 1 Accuracy evaluation of simulation result

\section{Conclusions}

In view of the dynamic characteristics of hydrological process, system dynamics method which performs well on describing complex feedback relationships is utilized to analyze the dynamic process of rainfall to runoff in the river basin. The water cycle dynamics model is established and the relationship between the variables in the model is determined by specific differential equations. A case study in the Zhexi river basin shows that the water cycle dynamics model is reliable on describing the dynamic process of rainfall to runoff in the river basin, and also achieve good performance on hydrological forecasting. The research on watershed water cycle simulation method based on system dynamics not only enriches the ideas of hydrological forecasting, but also expands the application of system dynamics in this field.

\section{Acknowledgements}

This work is funded by the National Key Research and Development Program of China (No. 2016YFC0402203) and the National Natural Science Foundation of China (No. 51779013, 51509009). Special thanks are given to the 
anonymous reviewers and editors for their constructive comments.

\section{References}

1. Karnopp D, Rosenberg R, Perelson A S. System Dynamics: A Unified Approach[J]. IEEE Transactions on Systems Man \& Cybernetics, 2007, SMC-6(10):724-724.

2. Khan S, Luo Y F, Ahmad A. Analysing complex behaviour of hydrological systems through a system dynamics approach[J]. Environmental Modelling \& Software, 2009, 24(12):1363-1372.

3. AMINELSHORBAGY, Jutla A, Kells J. Simulation of the hydrological processes on reconstructed watersheds using system dynamics[J]. International Association of Scientific Hydrology Bulletin, 2007, 52(3):538-562.

4. Keshta N, Elshorbagy A, Carey S. A generic system dynamics model for simulating and evaluating the hydrological performance of reconstructed watersheds $[\mathrm{J}]$. Hydrology and Earth System Sciences, 13,6(2009-06-22), 2009, 5(3):865-881.

5. Renjun Z, Yilin Z, Lerun F, et al. The Xinanjiang model[J]. Proc of the Oxford Symposium on Hydrological Forecasting Iahs Publ, 1980, 135(1):371-381.

6. Yang K, Xiao-Bo R, You Y. Application of Xinanjiang Model in Mawang River Basin Runoff Simulation[J]. Journal of Zhejiang University of Water Resources \& Electric Power, 2017. 